\title{
La concepción socio-política y económica de Bolívar en la primera etapa de la guerra por la independencia de la Nueva Granada, $1810-1816^{*}$
}

\author{
Bolivar's Socio-Political and Economic \\ Conception in the First Stage of the War for \\ Nueva Granada's Independence, 1810-1816
}

\section{Ildebrando Arévalo Osorio **}

Recibido: 01/12/2013

Aprobado Evaluador Interno: 12/01/2014

Aprobado Evaluador Externo: 18/02/2014

\section{Resumen}

Este trabajo tiene como objeto analizar el pensamiento y la acción de Bolívar sobre las propuestas y las acciones de los independentistas neogranadinos entre 1810 y 1816 que se encontraban divididas alrededor del federalismo y el centralismo. Bolívar optó por una propuesta centralista en el orden político del contexto de la guerra, en las contradicciones sociales, la gran extensión y diversidad del territorio y la situación internacional; paralelamente, optó por la democracia en el ámbito social. Este trabajo se realiza bajo un enfoque hermenéutico: se estudian diversas fuentes primarias, tales como proclamas, discursos, cartas y decretos

\section{Abstract}

This work aims to analyze the thinking and action of Bolivar on proposals and actions of Independent "Neogranadinos" between 1810 and 1816 that were divided about federalism and centralism. Bolívar opted for a centralist political proposal in the context of war, social ambiguities, the vastness and diversity of the territory and the international circumstances; parallel, opted for democracy in the social realm. This work is performed under a hermeneutical approach: various primary sources, such as proclamations, speeches, letters and decrees elaborated by Bolivar and through these are reviewed, reconstructed, study explain and

doi:10.11144/Javeriana.PAPO19-1.cspe

* Artículo de investigación realizado en el marco del Master of Arts en Historia de la Universidad de la Amistad de los Pueblos con Rusia, Moscú.

** Magíster en Historia Andina de la Universidad del Valle, Master of Arts en Historia de la Universidad de los Pueblos con Rusia, Profesor de dedicación exclusiva la Universidad Santiago de Cali. Miembro del grupo de investigación Complexus, categoría D de Colciencias. Correo electrónico: brando240258@hotmail.com. 
elaborados por Bolívar y a través de estas se revisan, reconstruyen, explican e interpretan las continuidades y los cambios de la concepción de él obre la sociedad, la política y la economía en la Nueva Granada entre 1815 y 1816, que finalmente estuvo encaminada a reducir la desigualdad social para fortalecer las bases sociales del ejército popular y acelerar el proceso liberador.

\section{Palabras clave:}

pensamiento; concepción; Independencia; guerra; sociedad; democracia; política; Colombia interpret continuities and changes in the conception of society , politics and the economy in New Granada between 1815 and 1816 , and was eventually intended to reduce social disparity to strengthen the social foundations of the people's army and accelerate the freedom process.

\section{Keywords:}

thought; conception; Independence; war; society; democracy; politics; Colombia 


\section{Introducción}

La vida y obra de Bolívar ha motivado a intelectuales, políticos, activistas de movimientos sociales, hombres y mujeres de todas las condiciones sociales de América Latina y del mundo entero a la reflexión. A 200 años de distancia, cuando se convirtió en el Libertador de cinco repúblicas y en padre de sus cinco naciones, en Colombia y en el mundo se estudia su obra y se debaten diferentes tópicos sobre sus logros y fracasos. En este artículo el objeto de indagación y análisis es el periplo del libertador en la primera etapa de la guerra por la Independencia de la Nueva Granada en 1810-1816, su concepción socio-política y económica, sus representaciones e impronta en el devenir del proceso histórico. Desde su vinculación a las luchas independentistas granadinas, Bolívar se mostró como un demócrata decidido (Marchuk, 1999), partidario de adelantar la guerra apoyado en los sectores subalternos de campesinos, peones, vaqueros, indígenas, jornaleros y esclavos. Al mismo tiempo combatió la ideología y los métodos de conducción de las élites que detentaban el poder político, el militar y el administrativo y obstruían la gesta independentista. En oposición a ello y al calor de las experiencias de la guerra, Bolívar profundizó las acciones militares acompañadas de medidas sociales favorables a los sectores subalternos. Un ejemplo fue la eliminación de la esclavitud para aquellos esclavos que participaron en el ejército patriota.

En la historiografía bolivariana, este período se ha interpretado heterogéneamente como guerra fratricida, guerra internacional, guerra civil, como revolución a favor de los criollos o mantuanos con el fin exclusivo de imponer un proyecto hegemónico de clase o como una revolución social traicionada (Leal y Falcón, 2009, p. 61).

\section{Pensamiento socio - político}

A la edad de 25 años, en noviembre de 1812, Simón Bolívar se presentó por primera vez en la Nueva Granada, después de la caída de la Primera Republica venezolana. Llegó a Cartagena donde el gobierno de la provincia no disponía de muchos cuadros preparados militarmente. Por esta razón, el gobernador de la ciudad, José María Torices, acogió bajo su servicio a Bolívar y a los venezolanos que lo acompañaban. Sin embargo, las fuerzas armadas granadinas en Cartagena eran mandadas por el oficial francés Labatute que había venido a América con Miranda. ${ }^{1}$ Labatute, enterado que

${ }^{1}$ El 25 de julio de 1812, el ejército republicano de Venezuela estaba cercado en La Victoria, en inmediaciones a Caracas, por las fuerzas realistas comandadas por Monteverde. En Puerto Cabello varios oficiales patriotas, entre ellos Bolívar luchaban por recuperar el fuerte de San Felipe y confiaban en la ayuda de Miranda para culminar la acción y continuar la lucha. El General del ejército venezolano decidió capitular y delegar el mando. Esta acción fue interpretada por Bolívar y otros como traición a la patria. En el camino de la fuga de los españoles, Miranda y los jóvenes oficiales se encontraron en La Guaira. El General planeaba abordar el buque inglés Sapphire y abandonar Venezuela, lo cual fue impedido por los patriotas, quienes lo arrestaron y entregaron a Monteverde. Días más tarde, Bolívar logró obtener del comandante español un pasaporte y la 
Bolívar había participado en Venezuela en la detención de Miranda, no quiso aceptarlo inicialmente en su ejército (Arévalo, 1984, p. 14).

Por insistencia de Rodríguez Torices, el francés aceptó vincular a Bolívar al ejército; fue enviado en calidad de jefe de un pequeño destacamento a la población de Barracas, ubicada a las orillas del río Magdalena. Como punto estratégico Barracas tenía muy poco significado, y no jugaba un papel importante en las operaciones militares. Sin embargo, fue allí donde Bolívar inició su ascendente carrera militar (Liévano, 1979). En la primera etapa de la guerra de Independencia de la Nueva Granada el libertador actuó poco tiempo en su territorio, seis meses en total. Sin embargo, su accionar ejerció una decisiva influencia en el futuro acontecer de la guerra en el país.

Para comprender la situación política y militar en la Nueva Granada cuando Bolívar llegó es necesario hacer una descripción histórica. El 20 julio de 1810 en la capital del virreinato la población dirigida por los criollos se insurreccionó; el virrey Amar y Borbón fue depuesto por la Suprema Junta de Gobierno constituida por notables santafereños. En el Acta de la Independencia, la Suprema Junta proclamó el Reino de la Nueva Granada bajo el gobierno de Fernando VII (Ramírez, 1964, p. 37). Los acontecimientos de julio fueron un golpe de Estado llevado a cabo por personajes de la élite que aspiraban alinearse políticamente con el poder español y compartir con el virrey el poder político, conservando el aparato administrativo español (Ocampo, 1989, p. 18).

El 21 de julio de 1810, en un acto solemne, se inauguraron las sesiones de la Suprema Junta de Gobierno de Santa Fe, en donde se anunció la creación del sistema federativo como régimen de gobierno en cabeza de la antigua capital del virreinato, a pesar de que la mayoría de las otras provincias aspiraban a independizarse de la capital.

El 22 de julio en el barrio de San Victorino, bajo la dirección de José María Carbonell, los estudiantes de los colegios San Bartolomé y el Rosario auspiciaron la creación de una Junta Popular con participación de comerciantes adinerados, representantes de los artesanos y los jornaleros. En la práctica, esta junta se convirtió en un club revolucionario; allí se debatía sobre la soberanía popular, los derechos de los sectores subalternos, los acuerdos de la élite criolla con el virrey, las posibilidades y problemas de la proclamación de la Independencia del país y la constitución republicana del futuro Estado (Ilina, 1976). Entre los integrantes de la Junta Popular se encontraban criollos que compartían puntos de vista republicanos; sobresalían Antonio Nariño, José María Carbonell, Manuel García y Antonio Ricaurte.

salida del país. Los seguidores de Miranda consideraron la acción, como un complot contra su jefe (Grigulévich, 1978, pp. 120-129). 
La lucha entre la Junta Suprema y la Junta Popular reflejó el choque político que existía entre los diferentes grupos de la élite que aspiraban al dominio del incipiente Estado. La Junta Popular se apoyó en los sectores populares e intentó utilizar sus simpatías.

Mientras tanto, en las demás provincias acontecía un proceso semejante. Se crearon Juntas en Antioquia, Mompox, San Marta, Chocó, Casanare, Neiva, Mariquita y Tunja, y éstas se sumaron a las que ya existían en Cartagena y Socorro. De hecho, la Nueva Granada se transformó en 22 provincias independientes. Algunas de estas, como por ejemplo Cartagena, reconocían a Fernando VIII y al Consejo Regente; otras, Socorro y Pamplona, reconocieron a Fernando y desconocieron el Consejo Regente. En el norte y el sur del país, las provincias de Popayán, Río Hacha y Panamá continuaban bajo el poder de los españoles (Ilina, 1976).

El 24 de septiembre de 1810 la Suprema Junta de Gobierno de Santa Fe sancionó el decreto sobre la liquidación de los resguardos, y al mismo tiempo anunció la eliminación del tributo de indios. Estas medidas estaban dirigidas contra la población indígena que destruía la propiedad colectiva de la tierra y creaba las condiciones para el establecimiento de la propiedad privada. De esta manera, se condenaba a los antiguos comuneros a vender su fuerza de trabajo y a pagar impuestos como lo hacían los otros habitantes del reino. "Al nivelar a los indios con los otros súbditos, el Estado llevó a cabo una acción en correspondencia con las teorías de nuestro gobierno y sus intereses”, escribió Antonio Nariño (1982, p. 26).

Con las medidas anteriores, los criollos descargaron sobre los hombros de los indígenas pesadas obligaciones económicas y esta fue la causa por la cual amplios sectores subalternos de la población no apoyaron a la Junta, dirigida por notables que sesionaban a favor de intereses particulares.

El 27 de Febrero de 1811 fue creado el reino de Cundinamarca con capital en Santa Fe. El gobierno anunció la pretensión de unir todas las provincias de la Nueva Granada en un Estado centralizado. Nariño editó el periódico La Bagatela, en el cual argumentó la necesidad de un gobierno centralista como condición principal para defender la Independencia y fortalecer la economía del país. El 1 de abril se proclamó en Santa Fe la Constitución, la cual fortaleció el reino y declaró las libertades individuales de propiedad, comercio, industria y el derecho a la libre empresa (Ilina, 1984). A punto de culminar el año, el 11 de noviembre, Cartagena proclamó la total independencia de España.

El 7 de octubre de 1812 se organizó el nuevo Estado de las Provincias de la Nueva Granada bajo la conducción de Nariño. Alrededor de Cundinamarca se unieron Chocó, Mariquita, Neiva, Ambalema y otra serie de territorios. Entonces, el Congreso de las Provincias Unidas en la ciudad de Tunja que confederaba a Tunja, Antioquia, Cartagena y Neiva, donde gobernaban los federalistas liderados por el abogado Camilo Torres, le declaró la guerra a Cundinamarca. Así se inició la "Patria Boba”, una guerra civil entre patriotas granadinos (Universidad Nacional y Revista Semana, 2010, P. 53). 
Nariño, comprendió de la siguiente manera la situación política:

...a pesar que han transcurrido tres años la caja de las provincias está vacía, no existen fuerzas militares ni el servicio militar, ni el palacio para acuñar monedas, ni escuelas, ni caminos, etc. Solamente tenemos una enorme cifra de funcionarios, en el sostenimiento de los cuales se invierte todo el dinero conseguido, los cuales defienden con todas sus fuerzas el nuevo régimen de la misma manera que de él se benefician. (1982, p. 63)

Este era el panorama cuando Bolívar apareció en la Nueva Granada; llegó a Cartagena huyendo de los españoles después de ser derrotado en Venezuela. Inmediatamente presentó sus reflexiones a los patriotas neogranadinos en el documento conocido como Memoria dirigida los ciudadanos de la Nueva Granada por un caraqueño el 15 de diciembre de 1812. En él realizó un minucioso análisis de las causas de su derrota en Venezuela y sometió a la crítica las aspiraciones de los patriotas de organizar un régimen político federalista en los nuevos estados. Dijo el libertador:

Libertar a la Nueva Granada de la suerte de Venezuela, y redimir a ésta de la que padece, son los objetos que me he propuesto en esta Memoria. Dignaos, oh mis conciudadanos, de aceptarla con indulgencia en obsequio de miras tan laudables...

El sistema federal bien que sea el más perfecto y más capaz de proporcionar la Felicidad humana en sociedad es, no obstante, el más opuesto a los intereses de nuestros nacientes Estados. Generalmente hablando, todavía nuestros conciudadanos no se hallan en aptitud de ejercer por sí mismos ampliamente sus derechos; porque carecen de las virtudes políticas que caracterizan al verdadero republicano: virtudes que no se adquieren en los gobiernos absolutos, en donde se desconocen los derechos y los deberes del ciudadano...

Pero lo que debilitó más el Gobierno de Venezuela, fue la forma federal que adoptó, siguiendo las máximas exageradas de los derechos del hombre, que autorizándolo para que se rija por sí mismo rompe los pactos sociales, y constituye a las naciones en anarquía. Tal era el verdadero estado de la Confederación. Cada provincia se gobernaba independientemente; y, a ejemplo de éstas, cada ciudad pretendía iguales facultades alegando la práctica de aquéllas y la teoría de que todos los hombres, y todos los pueblos, gozan de la prerrogativa de instituir a su antojo, el gobierno que les acomode. (Bolívar en Rivas, 2010, pp. 56-6o)

En las condiciones impuestas por la guerra, Bolívar propuso un gobierno que se ajustase a la situación y se alejase de los regímenes políticos que creaban los criollos a imagen y semejanza de las teorías de gobierno elaboradas en Europa y en los Estados Unidos en contextos históricos diferentes: 
Por otra parte ¿qué país del mundo por morigerado y republicano que sea, podrá, en medio de las facciones intestinas y de una guerra exterior, regirse por un gobierno tan complicado y débil como el Federal? No, no es posible conservarlo en el tumulto de los combates y de los partidos. Es preciso que el gobierno se identifique, por decirlo así, al carácter de las circunstancias, de los tiempos y de los hombres que lo rodean. Si éstos son prósperos y serenos, él debe ser dulce y protector; pero si son calamitosos y turbulentos, él debe mostrarse terrible, y armarse de una firmeza igual a los peligros, sin atender a leyes ni constituciones, ínterin no se restablecen la Felicidad y la paz. (Bolivar en Rivas, 2010, pp. 60-61).

El libertador combatía como males nefastos para la revolución y la guerra libertadora la tiranía, opuesta a los ideales republicanos y la anarquía, nacida la opinión inveterada tanto de los dirigentes ignorantes y supersticiosos y de las capas dominantes como de las masas populares, alejados los unos y los otros del pensamiento ilustrado (Dessau, 2000).

En concordancia con esta representación, Bolívar señaló en El Manifiesto de Cartagena e13 de diciembre de 1812, las cinco causas principales que conllevaron a la caída de la Primera República en Venezuela:

...En primer lugar la naturaleza de su constitución que, repito, era tan contraria a sus intereses como favorable a la de sus contrarios. En segundo, el espíritu de misantropía que se apoderó de nuestros gobernantes. Tercero, la oposición al establecimiento de un cuerpo militar que salvase la República y repeliese los choques que le daban los españoles. Cuarto, el terremoto acompañado del fanatismo que logró sacar de este Fenómeno los más importantes resultados; y últimamente, las facciones internas que en realidad fueron el mortal veneno que hicieron descender la patria al sepulcro. (p. 16)

El balance realizado por el Libertador estaba dirigido a persuadir a las élites neogranadinas de la necesidad y la decisión de conservar la independencia de España. Bolívar era consciente de la dificultad de crear condiciones que posibilitaran la unión de los criollos y las fuerzas patriotas alrededor de un amplio programa político único, pues entre los sectores dirigentes había contradicciones de intereses muy fuertes. Algunas de las medidas propuestas por el Libertador incomodaban a los líderes de la mayoría de los gobiernos de las provincias que aspiraban a consolidar su influencia regional y local en detrimento del poder central; otras afectaban el espíritu religioso proclive a mantener el sometimiento al virreinato del gobierno hispano. Estos caudillos militares no tenían disposición positiva frente a la creación de una sola fuerza militar unida ni a realizar acciones de coacción a las órdenes religiosas para incautar sus propiedades eclesiásticas y solventar las necesidades de la guerra. La propuesta de Bolívar empezó a afectar y debilitar las posiciones de los círculos de terratenientes y dueños de plantaciones y esclavos; 
esto se reveló entre aquellos que constituían el sector con mayor capacidad económica para financiar y apoyar la guerra, interesados en conservar la Independencia y, al mismo tiempo, no perjudicar sus intereses de propietarios, esclavistas y caciques locales.

A finales de 1812, entre los pensamientos y las acciones de Bolívar tratados y analizados en el Manifiesto, no se destacó su interés en apoyarse decididamente en la fuerza que representaban los sectores subalternos, constituidos por campesinos, peones, vaqueros, indígenas, jornaleros, esclavos negros. Temía que ellos, una vez armados y compenetrados con propuestas que los decidiera a emplearse a fondo en la lucha que resolviera algunas de sus necesidades más sentidas, la propiedad, la libertad y la posesión de títulos sobre la tierra, aspirarían a redistribuir la tierra, a reclamar derechos como ciudadanos y a alterar las estructuras socioeconómicas vigentes. Bolívar basaba sus cálculos en una victoria militar en las circunstancias planteadas por la guerra. $\mathrm{Al}$ respecto escribió: "Así pues, no nos queda otro recurso para precavernos de estas calamidades, que el de pacificar rápidamente nuestras provincias sublevadas, para llevar después nuestras armas contra los enemigos; y formar, de este modo, soldados y oficiales dignos de llamarse las columnas de la patria” (1970, p. 19).

La preferencia y las conjeturas que realizaba Bolívar alrededor de la acción militar, a pesar de las desventajosas condiciones militares propiciadas por la división política del país y el apoyo que los sectores populares dispensaban a los ejércitos realistas, estaban fundamentadas en la convicción de su capacidad de convencer a los miembros del Congreso de las Provincias Unidas de la Nueva Granada de que el enemigo también se hallaba debilitado, que la guerra defensiva adelantada por los neogranadinos contra las fuerzas españolas era equivocada y que una guerra ofensiva era la más favorable para obtener en forma consecutiva dos objetivos: preservar la independencia de la Nueva Granada y liberar a la república de Venezuela. Así razonó Bolívar el 15 de diciembre de 1812:

Aprovechemos, pues, instantes tan propicios; no sea que los refuerzos que incesantemente deben llegar de España, cambien absolutamente el aspecto de los negocios, y perdamos, quizás para siempre, la dichosa oportunidad de asegurar la suerte de estos Estados.

El honor de la Nueva Granada exige imperiosamente escarmentar a esos osados invasores, persiguiéndolos hasta los últimos atrincheramientos, como su gloria depende de tomar a su cargo la empresa de marchar a Venezuela, a libertar la cuna de la independencia colombiana, sus mártires, y aquel benemérito pueblo caraqueño, cuyos clamores sólo se dirigen a sus amados compatriotas los granadinos, que ellos aguardan con una mortal impaciencia, como a sus redentores. Corramos a romper las cadenas de aquellas víctimas que gimen en las mazmorras, siempre esperando su salvación de vosotros; no burléis su confianza; no seáis insensibles a los lamentos de vuestros hermanos. Id veloces a vengar al muerto, a dar vida al moribundo, soltura al oprimido y libertad a todos. (Rivas, 2010, p. 66) 
Tres semanas antes de la escritura del Manifiesto de Cartagena, el 27 de noviembre, Bolívar envió una carta al Congreso de las Provincias Unidas de la Nueva Granada, que residía y sostenía sesiones en la ciudad de Tunja. En este documento caracterizó en un boceto general la situación política y militar que se vivía en Venezuela y expresó su opinión acerca del carácter de la lucha de las diferentes facciones venezolanas por el poder:

Más se apresuró la época de recibirlas, cuando el Congreso Federal se propuso por algunos
genios turbulentos ansiosos de dominar en sus ciudades y provincias, la división de la de
Caracas en pequeños estados que debilitaban más y más al Gobierno Federal, que por sí
mismo no es fuerte. Los fogosos y sostenidos debates, que sobre esta materia si tuvieron,
inspirados en los Pueblos, una desconfianza y odio contra Caracas, que originaron la subleva-
ción de la ciudad de Valencia, una de las más importantes de la provincia (Rivas, 2010 p. 54).

Bolívar indirectamente expresó su desazón por la incapacidad y la estrechez de comprensión que mostraban las élites de la ciudad de Caracas y las provincias, que ante la posibilidad de concentrar el poder político, militar y administrativo en un centro patriota para garantizar la Independencia, renunciaban a ello.

El 23 de diciembre de 1812, a la cabeza de un pequeño grupo de patriotas neogranadinos, Bolívar inició acciones militares a lo largo de las orillas del río Magdalena. Ese día se tomó Tenerife y el 1 de enero de 1813, Chiriguana. El 19 de enero el Congreso de la Nueva Granada le comunicó la presencia de tropas realistas bajo la conducción de Ramón Correa en la frontera oriental del país. Bolívar las derrotó y el 28 de Febrero de 1813 tomó por asalto a Cúcuta. El 7 de mayo recibió la orden del Congreso de iniciar la Campaña de Venezuela. El 7 de agosto de ese mismo año liberó Caracas (Liévano, 1979).

Mientras tanto, en la Nueva Granada los acontecimientos transcurrieron de manera diferente. Siguiendo los pasos de Cundinamarca, Antioquia rompió sus lazos con España el 20 de abril de 1814; posteriormente anunció el decreto de la liberación de los esclavos en los territorios de su provincia y se convirtió en el primer gobierno que realizó esta acción.

Sin embargo, pese a lo significativo de este acontecimiento, el fortalecimiento del poder de los partidarios del centralismo y el avance de los realistas por el sur amenazaron el poder del Congreso y la independencia de la Nueva Granada. Los dueños de las minas y los esclavistas mantuvieron un fuerte nexo con el poder español (Garrido, 2009). Entre sectores de la población se difundió un fuerte sentimiento pro hispánico, suscitado por las acciones del nuevo gobierno en relación con la población indígena. El presidente de Quito, Toribio Montes comprendió la favorable situación y desplegó una ofensiva contra los patriotas, encabezada por J. Solano a inicios de junio de 1813. El $1^{0}$ de julio, Solano, sin combatir, ocupó Popayán: en agosto ocupó toda la provincia, y antes de iniciar el camino hacia el norte envió un ultimátum a Nariño, conminándolo a 
capitular. Nariño inició conversaciones con el Congreso en Tunja para culminar la lucha entre federalistas y centralistas y renunció a sus obligaciones como dictador.

Los acontecimientos crearon condiciones para llevar a cabo acuerdos conducentes a unir las fuerzas de Cundinamarca y la Federación de las Provincias Unidas. Nariño fue designado comandante para la Campaña del sur. En la práctica, esto significó la separación de Nariño de la capital Santa Fe, el principal líder entre la población y el fortalecimiento de la aristocracia criolla.

El 21 de septiembre de 1813, las tropas unidas de Cundinamarca, Tunja y El Socorro, compuestas por 1200 infantes y 200 hombres a caballo y encabezadas por Antonio Nariño, partieron de Santa Fe; el 30 de diciembre sostuvieron el primer combate que culminó con la derrota de los españoles. Nariño ocupó Popayán, Solano escapó y se fortaleció en Pasto, donde recibió refuerzos de Quito y preparó otro ataque contra los patriotas. El 2 de mayo de 1814 los españoles nuevamente fueron derrotados en Cochabamba. Siguiendo al enemigo, Nariño llego a Tasines y el 9 de mayo venció nuevamente a los realistas, quienes retrocedieron a Pasto. Ante las cuantiosas pérdidas, los españoles decidieron abandonar la ciudad sin combatir y dirigirse a Quito. Aspirando fortalecer los éxitos obtenidos y ocupar la ciudad antes que sus habitantes prepararan la defensa, Nariño, con un batallón de granaderos, se movió a marchas forzadas a Pasto y dejó atrás el grueso de las tropas con el compromiso de que luego de descansar se le unirían en la mañana siguiente.

Sin embargo, los opositores de Nariño convencieron al coronel Rodríguez de mantener inmóviles las fuerzas la madrugada del 10 de mayo. Esa acción permitió al Cabildo de Pasto convocar a los indígenas de los resguardos, organizarlos y atacar el cuerpo de tropas de Nariño y cortarle la retirada a Tasines. Cuando los combates arreciaron en las afueras de Pasto, las tropas de Rodríguez se desplazaron a Popayán abandonando a Nariño a su suerte, quien fue capturado por los indígenas el 14 de mayo. Así concluyó la Campaña del sur (Ilina, 1976, pp. 215-222). Las reflexiones y advertencias de Bolívar sobre las desavenencias de los criollos y su derrota en la Nueva Granada se hicieron realidad.

Mientras tanto, con la ocupación de Caracas Bolívar concluyó la liberación del país. Fundó la Segunda República de Venezuela y recibió poderes ilimitados. La respuesta de las tropas realistas fue la reorganización y el hostigamiento a los patriotas. Sus fuerzas fueron recompuestas con llaneros, pastores, vaqueros y esclavos negros. A estos últimos, el oficial español Boves los declaró libres e inició una guerra clasista contra los sectores dominantes criollos. Bolívar no varió su táctica de guerra, insistió en la lucha militar sin acompañarla con medidas de corte social favorables a los sectores populares. En sus proclamas y escritos de 1812, 1813 y 1814 no menciona la posibilidad de eliminar la esclavitud, limitando en la práctica la ampliación de la base social de las tropas patriotas.

En julio de 1814 los realistas derrotaron al ejército libertador en Venezuela y Bolívar, junto a los restos de su tropa, regresó a la Nueva Granada por Cartagena hacia Tunja, en 
donde desde 1812 estaba instalado el Congreso Supremo que continuaba luchando contra el gobierno de Cundinamarca. El Congreso de las Provincias Unidas de la Nueva Granada envió a Bolívar a Bogotá para que con la fuerza de las armas sometiera a Cundinamarca y la uniera a la Federación de la Nueva Granada. El 12 de diciembre de 1814 el ejército de Bolívar entró a Bogotá, Cundinamarca fue anexada a la Federación granadina, en enero de 1815 el Congreso Supremo se trasladó a Santa Fe y el gobierno Federal inmediatamente encargó a Bolívar dirigirse al norte, pues Santa Martha había sido ocupada por los realistas.

Existe un documento clave para analizar el pensamiento de Bolívar en su segunda estancia en la Nueva Granada, "La carta al excelentísimo señor presidente de la república del gobierno general de la Nueva Granada" (1981). En la misiva enviada a Camilo Torres el 22 de enero de 1815, el libertador describió cómo a pesar de que el gobierno Federal sometió con la fuerza de las armas a la mayoría de las provincias, el espíritu del separatismo continuó imperando en el ánimo de los dirigentes locales. Aunque él fue designado comandante general del ejército Federal, el coronel Manuel Castillo, comandante de la plaza y presidente del gobierno de la provincia de Cartagena, se negó a reconocer su autoridad. El Congreso de las Provincias Unidas se vio obligado a enviar tropas con las cuales Bolívar sometiera a Cartagena. Estos acontecimientos transcurrían cuando hacia la ciudad se dirigía una flota de la armada española, encabezada por Pablo Morrillo, con el objetivo de pacificar la Nueva Granada. Bolívar describió así la situación:

\footnotetext{
Por otra parte, estando pronto ya para partir por orden de V. E. hacia Cartagena, a restablecer la calma que el coronel Castillo ha alterado, desobedeciendo al gobierno de aquellas provincias; a formar el ejército que aquel jefe ha disuelto; a castigar a los tiranos, que aquel cobarde ha temido; y a libertar a Santa Marta, que no se ha atrevido, ni aun a atacar, no tengo tiempo para escribir, y voy a responder libertando más provincias que las que él ha destruido con su incapacidad y timidez. (Bolívar en Rivas, 2010, pp. 300-301)
}

No obstante, en esta ocasión la campaña no resultó exitosa; como el gobierno de Cartagena no le facilitó a Bolívar ni armas ni tropas, el libertador, derrotado, se embarcó para la isla de Jamaica (Ganiovski, 1973). El ejército regular patriota de los neogranadinos mantuvo una tenaz resistencia a lo largo de todo el año hasta que sus restos fueron aplastados en julio de 1816 .

\section{Pensamiento económico}

Algunos documentos escritos por el libertador a mediados de 1814 expresan claramente sus puntos de vista sobre la economía de los países de América Latina, las relaciones económicas internacionales de las antiguas colonias españolas, el papel de las clases sociales en la Independencia y la estructura política de los futuros Estados latinoamericanos. 
En la capital de Venezuela, en La Gaceta de Caracas Bolívar publicó el artículo Reflexiones sobre la situación actual de Europa y América el 28 de abril de 1814. Comentó los últimos acontecimientos europeos; la derrota de Napoleón en Leipzig en 1813 y el ascenso al trono de Fernando VII en 1814. El libertador se preguntó cuál sería la influencia de ellos en el destino de las antiguas colonias españolas y respondió afirmando la confianza en los pueblos americanos que lograrían triunfar en sus luchas de Independencia, que conservarían su soberanía con la formación de nuevas repúblicas y su decidida participación en la economía internacional. Para ello era necesario el desarrollo económico independiente de la América hispana a través del amplio intercambio comercial con las potencias europeas, para las cuales, en su opinión, sería rentable comerciar con las nuevas repúblicas:

\begin{abstract}
Hasta cuándo la belleza y la riqueza de nuestro continente, sus minas y tesoros serán dominio exclusivo de la voracidad de una potencia, la cual con sus leyes bárbaras ha traído en el transcurso de tres siglos la desagracia a millones de personas. Es difícil imaginar esto en la medida que ello no se corresponda con los intereses de las potencias mercantiles, las cuales hallaran en América un excelente mercado para sus mercancías, el cordial reconocimiento de sus habitantes y de las riquezas locales, las cuales - si se logran liberar de cualquier limitación, son el resultado de inimaginable ansiedad - serán favorables para ambos continentes. (1983, p. 45)
\end{abstract}

El 14 de julio de 1814 Bolívar escribió un nuevo artículo donde continuó las Reflexiones sobre la situación de Europa y América. En el escrito profundizó el análisis y llegó a la conclusión de que podría suceder que después de alcanzar la Independencia de los países de la América hispana, cualquier potencia europea intentara invadir y ocupar las antiguas colonias españolas. Bolívar preguntaba:

\footnotetext{
Después de la caída del poder de Napoleón, ¿es posible encontrar otro enemigo para el dominio inglés? Puede el mismo zar Alejandro, el cual se encuentra a la cabeza de los aliados en la lucha contra Napoleón, mañana intervenir en la conformación de una alianza continental más fuerte que todas las existentes hasta hoy. En estas condiciones de la política europea, ¿quisiera Inglaterra que América se encuentre bajo la dependencia de cualquier potencia continental, que su numerosa población y considerable riqueza aumente el poderío de aquellos países capaces de competir con Inglaterra? (1970, p. 31)
}

Bolívar comprendió que la independencia de los países latinoamericanos era un movimiento favorable para Inglaterra en las relaciones internacionales, captó que la potencia monopolista comercial marítima prontamente se interesaría en establecer 
relaciones de intercambio con el socio menor que se estaba formando. Para fortalecer las capacidades de negociación de los jóvenes Estados, Bolívar se propuso llevar a cabo una política de unión entre los estados latinoamericanos como consecuencia inmediata del proceso independentista que se gestaba en esos momentos en el continente.

Bolívar previó que, en caso de organizarse una coalición anti latinoamericana para agredir y someter nuevamente a los países que estaban logrando la Independencia, la consecuencia inmediata sería el inicio de una guerra civil que traería miseria y desolación al continente americano. Por ello, para evitar la guerra, se dirigió a diferentes naciones europeas, especialmente a Inglaterra, con la propuesta de fortalecer los canales que agilizaran el desarrollo del comercio. De esta manera se evitaría la destrucción que ocasionan los conflictos y el desarrollo industrial de las potencias europeas se vería beneficiado directamente. En sus meditaciones Bolívar se esforzó en construir argumentos para evitar una colisión a partir de las contradicciones que surgirían entre Europa y Latinoamérica.

Como resultado del análisis de la división internacional del trabajo que se aceleraba a inicios del siglo XIX, el libertador concluyó que entre Inglaterra y América Latina se podían establecer relaciones comerciales igualitarias, pues de parte de los latinoamericanos no había condiciones para emprender acciones que amenazaran el predominio de las potencias europeas que se dedicaban a la industria y al comercio. Las nuevas naciones deberían, durante un largo tiempo, dedicarse a la producción agrícola y minera que abastecería el mercado europeo con las materias y productos que éste requería. Estas serían las condiciones deseables para desarrollar relaciones amistosas con los países industriales y comerciales: "Nosotros no podemos imaginarnos la producción social, el nivel que alcanzará anualmente; al menos hasta el momento que sea reconocida nuestra independencia y nuestro comercio estén libres de extranjeros. Las mercancías para el mercado externo se ampliarán y las importaciones se irán nivelando con nuestra producción" (Bolívar, 1970 p. 31-33).

En estas reflexiones se evidenció la comprensión de Bolívar de la fuerte contradicción entre las colonias latinoamericanas que se independizaban y las exigencias de las potencias europeas a estos pueblos y territorios. El pensador soviético Iusee Grigulevich resaltó este aspecto:

Las revoluciones latinoamericanas, estando relacionadas con la revolución mundial burguesa, paralelamente entraban en una contradicción dialéctica, pues la burguesía europea requería de las colonias no menos de lo que la necesitaban los regímenes absolutistas y feudales que subyugaban el continente. Es necesario llamar la atención que estas contradicciones entre América Latina y Europa occidental en el siglo XIX nos ofrecen la clave para la compresión de la posterior dependencia de esta región de las potencias (1980, p. 12). 
Bolívar vio la posibilidad de solucionar estas contradicciones en la conformación de una alianza de las antiguas colonias hispanas e identificó las dificultades para ello en la "Contestación de un americano meridional a un caballero de esta isla":

Es una idea grandiosa pretender formar de todo el Mundo Nuevo una sola nación con un solo vínculo que ligue sus partes entre sí y con el todo. Ya que tiene un origen, una lengua, unas costumbres y una religión, debería por consiguiente tener un solo goobierno que confederase los diferentes estados que hayan de formarse; más no es posible, porque climas remotos. Situaciones diversas, intereses opuestos, caracteres desemejantes, dividen a la América (Arévalo, 1984, p. 57).

Las preocupaciones del Libertador acerca del mediato futuro de la Nueva Granada ocuparon parte de su tiempo y escritura. En el documento arriba citado, también conocido como "La Carta de Jamaica", el interrelacionó el desarrollo del futuro estado con el régimen republicano. Argumentó que los pueblos que se liberaban todavía no tenían ni la experiencia ni dominaban las formas que se exigen para el establecimiento del sistema Federal y sugirió que: "los americanos aspiran a conquistar la paz, al desarrollo de las ciencias, las artes, el comercio y la agricultura, prefieren las repúblicas a las monarquías, y nos parece, que sus esperanzas no se corresponden con los puntos de vista de Europa" (1970, p. 33-34).

Bolívar precisó este pensamiento con las experiencias de la Nueva Granada y Venezuela. De nuevo insistió en la necesidad de que estos países se especializaran en la agricultura y el dominio de la ganadería, e insinuó la civilización de los indígenas que habitaban la desértica región de la Guajira. A diferencia de los métodos utilizados en los Estados Unidos para colonizar las tierras de los indígenas, Bolívar planteó su conservación a través de la inclusión en el modelo civilizador occidental:

La Nueva Granada se unirá con Venezuela, si llegan a convenirse en formar una república central, cuya capital sea Maracaibo o una nueva ciudad que con el nombre de Las Casas (en honor de este héroe de la filantropía), se funde entre los confines de ambos países, en el soberbio puerto de Bahía Honda. Esta posición aunque desconocida, es más ventajosa por todos respectos. Su acceso es fácil y su situación tan fuerte, que puede hacerse inexpugnable. Posee un clima puro y saludable, un territorio tan propio para la agricultura como para la cría de ganados, y una gran abundancia de maderas de construcción. Los salvajes que la habitan serían civilizados, y nuestras posesiones se aumentarían con la adquisición de la Guajira. Esta nación se llamaría Colombia como tributo de justicia y gratitud al creador de nuestro hemisferio. (1970, p. 35).

Para la mayoría de los contemporáneos de Bolívar, europeos y americanos, la principal dificultad para alcanzar la Independencia de las colonias españolas en América la constituyó 
la existencia del régimen de castas en el cual se dividía la población de estos territorios. Por su parte, Bolívar entendió que las contradicciones entre castas no eran la causa principal de la revolución social, que éste sólo era uno de los aspectos de la manifestación del conflicto económico, social y cultural. La principal causa de la revolución suramericana a comienzos del siglo XIX, en su opinión, la configuraba la discrepancia entre las diferentes opciones políticas, consecuencia de las ambiciones de los individuos de las élites, de grupos disconformes que defendían intereses económicos estrechos y se habían conformado en vísperas de la Independencia en la parte meridional de América. "Las diferentes manifestaciones de violencia en América nunca se originaron en la lucha entre castas, irreconciliables discordias surgieron en los disentimientos en las opiniones políticas, como consecuencia de las ambiciones de uno u otro individuo, es decir, por causas similares que ocasionan la cizaña en cualquiera de los demás pueblos” (Bolívar en Lavretski, 1882, pp. 65-66).

Identificando el cambio positivo de la situación social y económica de población granadina y meridional con la necesaria reorganización social, Bolívar entendió que la mayoría de los diferentes productores vivían en condiciones de desigualdad y miseria. De allí dedujo la necesidad de instaurar nuevos gobiernos capaces de transformar este orden social con la deseable cooperación de las potencias europeas para la causa de la Independencia. Consecuencialmente, los grupos constitutivos de la nueva élite nacional que casi no disponían de nexos con la economía de la metrópoli, y por lo tanto se encontraban imposibilitados para encontrar apoyo en la lucha contra España, deberían promover propuestas de orden social relacionadas con las necesidades e intereses de los sectores populares. Bolívar era consciente de que tales medidas no eran las que la élite de las antiguas colonias quisiera promover, por ser opuestas a sus intereses inmediatos:

Obsérvese además la diferencia que existe entre los cautivos de la antigüedad y los miserables trabajadores de la América: aquéllos eran prisioneros de guerra, acostumbrados al manejo de las armas, mercaderes y navegantes ricos, filósofos profundamente instruidos, que conocían sus derechos y todos sufrían impacientes las cadenas. Los modernos son de una raza salvaje, mantenidos en la rusticidad por la profesión a que se les aplica y degradados a la esfera de los brutos.

Lo que es, en mi opinión, realmente temible es la indiferencia con que la Europa ha mirado hasta hoy la lucha de la justicia contra la opresión, por temor de aumentar la anarquía; ésta es una instigación contra el orden, la prosperidad, y los brillantes destinos que esperan a la América. El abandono en que se nos ha dejado es el motivo que puede, en algún tiempo, desesperar al partido independiente, hasta hacerlo proclamar máximas demagógicas para atraerse la causa popular; esta indiferencia repito es una causa inmediata que puede producir la subversión y que sin duda forzará al partido débil en algunas partes de la América a adoptar medidas, las más perniciosas, pero las más necesarias para la 
salvación de los americanos que actualmente se hallan comprometidos en la defensa de su patria, contra una persecución desconocida en todo otro país que la América española.

La desesperación no escoge los medios que la sacan del peligro (1983, p. 68)

\section{Conclusión}

Para Bolívar, tanto en la Nueva Granada como en las nuevas naciones en formación, existió la posibilidad de promover las ideas de libertad, patria y propiedad en correspondencia con las condiciones reales de vida de sus habitantes en la guerra de Independencia entre 1810 y 1816. En el subcontinente suramericano, en donde la absoluta mayoría de sus habitantes se encontraba en condiciones deprimentes y vivía en la ignorancia, para atraer a estos habitantes a la causa de la Independencia era necesario que la élite económica y social les hubiese presentado un programa de transformaciones sociales comprensible. Ellos habrían comprendido la guerra de Independencia a partir de medidas que consideraran la distribución de la tierra, la liquidación de impuestos y de decisiones prohibitivas que impedían el desarrollo del comercio y la agricultura, que apoyaran a los campesinos en el cultivo de la tierra, a los trabajadores en el desarrollo de sus oficios y a los pequeños ganaderos en la cría y comercio del ganado. Estas medidas tuvieron posibilidad de realizarse en la medida en que la nueva economía latinoamericana hubiese logrado negociar ventajosamente con la expansión industrial y comercial de las naciones europeas, las cuales requerían de su producción agrícola y ganadera. En síntesis, se necesitaban medidas que propiciaran la solución tanto de las necesidades populares como de los intereses reales de las nuevas élites; estas medidas hubiesen posibles si las élites hubieran optado por un programa de gobierno que desbordara sus intereses inmediatos y propiciara un modelo de régimen social democrático.

\section{Referencias Bibliográficas}

Arévalo O., I. (1984). Simón Bolívar y la lucha por la independencia de la Nueva Granada. Moscú: Universidad de la Amistad con los Pueblos.

Bolívar, S. (Septiembre de 1815). Señor redactor o editor de la Gaceta Real de Jamaica. Kingston. En V.V. Volski, I. R. Grigulévich, y A. F. Shulgovski (comps.), Simon Bolivar. Obras escogidas: discursos, artículos, cartas, liamamientos, 1812-1830 (pp. 65 - 69). Moscú; Nauka.

Bolívar, S. (1970). Documentos. Los orígenes de la dependencia neocolonial. Bogotá: Frente de Estudios Sociales, Fundación Editorial.

Bolívar, S. (1981). Carta al Soberano Congreso de la Nueva Granada. Cómo nació la República de Colombia. Bogotá: Banco de la República. 
Bolívar, S. (1982). Contestación de un americano meridional a un caballero de esta isla. Bogotá: Oveja Negra.

Dessau, A. (2000). Bolívar en la historia del pensamiento filosófico y político de América Latina. Caracas: Ediciones Anfictiónicas.

Ganiovsky, S. A. (1973). Colombia. Moscú: Editorial Moscú.

Garrido, M. (2009). "Nueva Granada entre el orden colonial y el republicano: lenguaje e imaginarios sociales y políticos”. En: Palacios, M. (Coordinador.). Las independencias hispanoamericanas. Bogotá: Norma, pp. 93-125.

Grigulevich, I. P. (1980) Bolívar, Nuestro contemporáneo. Revista América Latina, No. $10,4-13$.

Ilina, N. G. (1976). Colombia: de la colonia hasta la independencia. 1781-1819. Moscú: Nauka.

Ilina, N. G. (1984). La guerra de Independencia en Colombia (1810-1824). Moscú: Nauka.

Lavretski (Grigulevich), I. P. (1882). Simón Bolívar. Moscú: Progreso.

Leal, C. y Falcón, F. (2009). Las tres independencias de Venezuela: entre la lealtad y la libertad (1808-1830). En: M. Palacios (Coord.), Las independencias hispanoamericanas (pp. 61-92). Bogotá: Norma.

Liévano, A, I. (1979). Bolívar. Bogotá: Oveja Negra.

Marchuk, N. N. (1999). Las reformas liberales y la guerra de independencia de Latinoamérica. Moscú: Prometeo.

Nariño, A. (1982). Escritos políticos. Bogotá: El Ancora Editores.

Ocampo, J. (1989). El proceso político, militar y social de la independencia. En: C. Calderón (Coord.), Nueva Historia de Colombia (Vol. 2) (pp.9-64). Bogotá: Planeta.

Ramírez, E. P. (1964). Colombia. La Habana: Editorial Ciencias Sociales.

Rivas, G. (Comp.). (2010). Simón Bolivar. Obras completas (Vol 1.). Bogotá: FICA.

Universidad Nacional de Colombia y Revista Semana (2010). La Patria Boba no, la Primera República. En, J. F. Hoyos (Ed.), Colombia, 200 años de identidad (Tomo 1) (pp. 54-53). Bogotá: Universidad Nacional de Colombia y Revista Semana.

Volski, V. V., Grigulevich, I. P. y Shulgovski, A. F. (1983). Simon Bolivar. Obras escogidas: discursos, artículos, cartas, liamamientos, 1812-1830. Moscú: Nauka. 
